\title{
Los criterios básicos de clasificación de la materia: concepciones y niveles de competencia en alumnos y futuros maestros de Primaria
}

\section{The basic criteria for the classification of matter: conceptions and levels of competence in students and prospective teachers in Primary}

\author{
Paloma GALÁN MARTÍN y Rosa MARTÍN DEL POZO \\ Universidad Complutense de Madrid
}

Recibido: Febrero 2012

Aceptado: Marzo 2012

\begin{abstract}
Resumen
En este artículo se describen, analizan y comparan los criterios que, una muestra de 55 alumnos de los tres ciclos de Primaria y 55 estudiantes del Grado de Maestro, utilizan para clasificar la materia y cómo emplean los criterios básicos de clasificación (vivo / no vivo) a partir de los datos suministrados por una tarea de clasificación de imágenes elaborada a tal efecto ${ }^{1}$. Los resultados indican que todos utilizan una gran diversidad de criterios, destacando la comida como criterio espontáneo y la asociación vivo-movimiento en Primaria, mientras que el carácter vivo/no vivo y las funciones vitales son criterios mayoritarios entre los futuros maestros, pero sin aplicar un concepto de vida científicamente aceptable. Por último, se proponen diferentes niveles de competencia en la clasificación de la materia y se señalan implicaciones para la enseñanza y la formación inicial de maestros.
\end{abstract}

Palabras clave: Educación Primaria, Formación inicial de maestros, Clasificación de la materia, Concepciones de los alumnos, Niveles de competencia.

\begin{abstract}
This article will describe, analyze and compare the criteria that a sample of 55 students from the three primary cycles and 55 prospective teachers used to classify the material and how they use the basic criteria of classification (alive / not live) from data supplied by an image classification task developed for this purpose. The results indicate that all use a variety of criteria, emphasizing the food and spontaneous approach and partnership in primary live-motion, while
\end{abstract}

\footnotetext{
${ }^{1}$ Este artículo es parte del Trabajo Fin de Máster "Los criterios de clasificación de la materia en la Educación Primaria: Concepciones de los alumnos y niveles de competencia" en el Máster Universitario de Estudios Avanzados en Pedagogía de la Universidad Complutense de Madrid, que ha tenido continuidad ampliándose la muestra a estudiantes universitarios de $3^{\circ}$ año del Grado Maestro de Primaria en la Facultad de Educación de la citada universidad.
} 
the character alive / not alive and vital functions are major criteria among future teachers, but without applying a concept of life scientifically acceptable and consistent with the content of formal education. Finally, we propose different levels of competency in the classification of the subject and identifies implications for teaching and teacher education.

Keywords: Primary Education, Initial teacher training, Classification of matter, Conceptions of students, Levels of competency.

Durante las últimas tres décadas se ha desarrollado una línea de investigación en Didáctica de las Ciencias en la que se pretende, básicamente, averiguar lo que los alumnos saben al iniciar, finalizar o durante el proceso de enseñanza-aprendizaje de algún tópico del currículo de Ciencias de la Naturaleza. En estos trabajos se ha ofrecido información no solo sobre el contenido de tales ideas sino también sobre cuál puede ser su origen, cómo están organizadas y con qué estrategias didácticas pueden cambiar o evolucionar (Posada, 2000)

Muchos de los contenidos científicos que aparecen en el currículo escolar han sido estudiados desde el punto de vista de las concepciones que tienen los alumnos de diferentes niveles educativos. En este sentido son más frecuentes los que tienen que ver con las ciencias físico-químicas que con las ciencias naturales (Biología y Geología), y también más frecuentes en muestras de alumnos de Secundaria que de Primaria (Furió et al., 2006), y más en muestras de alumnos que de futuros maestros.

En el nivel de Primaria, uno de los contenidos curriculares que ha sido poco estudiado desde esta perspectiva se refiere a los criterios que los alumnos utilizan para clasificar la materia y cómo utilizan un criterio básico de clasificación: vivo/no vivo. Sin embargo, la clasificación es uno de los procesos científicos básicos que forman parte de la competencia científica (competencia en el conocimiento e interacción con el mundo fisico, según la denominación del currículo de Primaria), que se evalúa en los países de la Unión Europea y que los alumnos de Primaria han de ir desarrollando a lo largo de los diferentes ciclos. Este proceso se aplica tanto en la materia inerte como en los seres vivos, que son contenidos curriculares de gran presencia en la Educación Primaria y por consiguiente, en la formación inicial de maestros.

Así pues, dentro de esta línea de investigación, hemos realizado un estudio cuya finalidad es averiguar qué criterios utilizan espontáneamente los alumnos de Primaria y los futuros maestros de la muestra para clasificar la materia y cómo utilizan el criterio básico de clasificación vivo/no vivo.

\section{La clasificación de la materia en el currículo de la Educación Primaria y de la formación de futuros maestros}

En los requisitos para la verificación de los títulos universitarios oficiales que habilitan para el ejercicio de la profesión de Maestro en Educación Primaria (ORDEN ECI/3857/2007), más concretamente, en el Módulo Didáctico y Disciplinar (Ciencias Experimentales, Sociales, Matemáticas, Lenguas, Educación Musical, Plástica y 
Visual, y Educación Física) se dice que los futuros maestros deben ser capaces, en cada una de las áreas curriculares, de promover la adquisición de competencias básicas en los alumnos de Primaria. Además, se indica que deben de:
a) Comprender los principios básicos y las leyes fundamentales de las ciencias experimentales (Física, Química, Biología y Geología).
b) Conocer el currículo escolar de estas ciencias.
c) Promover la adquisición de competencias básicas en los alumnos de Primaria.

Por su parte, en el currículo oficial de Educación Primaria (ORDEN ECI/2211/2007), la competencia en el conocimiento y la interacción con el medio físico incluye el progresivo dominio de procesos científicos básicos, como el de la clasificación. Los contenidos relacionados con la clasificación de la materia están incluidos en dos bloques de contenido: uno sobre la materia viva y otro sobre la materia inerte (Tabla 1). A lo largo de los tres ciclos de la Educación Primaria se van incluyendo diferentes criterios de clasificación cada vez de mayor complejidad.

\begin{tabular}{|c|c|c|}
\hline CICLOS & $\begin{array}{c}\text { BLOQUE } 2 . \\
\text { LA DIVERSIDAD DE LOS SERES } \\
\text { VIVOS }\end{array}$ & $\begin{array}{c}\text { BLOQUE } 6 . \\
\text { MATERIA Y ENERGÍA }\end{array}$ \\
\hline $\begin{array}{l}\text { PRIMER } \\
\text { CICLO } \\
(6-8 \text { años) }\end{array}$ & $\begin{array}{l}\text { - Observación de múltiples formas de } \\
\text { vida. Identificación de diferencias entre } \\
\text { seres vivos y objetos inertes. } \\
\text { - Observación directa e indirecta de } \\
\text { animales y plantas. Clasificación según } \\
\text { elementos observables, identificación y } \\
\text { denominación. } \\
\text { - Asociación de rasgos físicos y pautas } \\
\text { de comportamiento de plantas y } \\
\text { animales con los entornos en los que } \\
\text { viven (camuflaje, cambio de color, } \\
\text { grosor del pelaje, etc.) }\end{array}$ & $\begin{array}{l}\text { La diversidad de materiales. } \\
\text { Clasificación según criterios } \\
\text { elementales: estado de agregación, } \\
\text { textura, color, forma, plasticidad, } \\
\text { etc. }\end{array}$ \\
\hline $\begin{array}{l}\text { SEGUNDO } \\
\text { CICLO } \\
\text { (8-10 años) }\end{array}$ & $\begin{array}{l}\text { - Animales vertebrados e invertebrados. } \\
\text { Aves, mamíferos, reptiles, peces, } \\
\text { anfibios. Características básicas, } \\
\text { reconocimiento y clasificación. } \\
\text { - Plantas: hierbas, arbustos y árboles. } \\
\text { Características, reconocimiento y } \\
\text { clasificación. } \\
\text { - La nutrición, relación y reproducción } \\
\text { de animales y plantas. Clasificación de } \\
\text { animales y plantas en relación con las } \\
\text { funciones vitales. } \\
\text { - Observación directa de seres vivos, con } \\
\text { instrumentos apropiados y a través del } \\
\text { uso de medios audiovisuales y } \\
\text { tecnológicos. }\end{array}$ & $\begin{array}{l}\text { Comparación, clasificación y } \\
\text { ordenación de diferentes objetos } \\
\text { y materiales a partir de } \\
\text { propiedades físicas observables y } \\
\text { posibilidades de uso. }\end{array}$ \\
\hline
\end{tabular}




\begin{tabular}{|c|c|c|}
\hline $\begin{array}{l}\text { TERCER } \\
\text { CICLO } \\
\text { (10-12 años) }\end{array}$ & $\begin{array}{l}\text { - La estructura y fisiología de las } \\
\text { plantas. } \\
\text { - Uso de claves y guías de identificación } \\
\text { de animales y plantas. } \\
\text { - Observación y registro de algún } \\
\text { proceso asociado a la vida de los seres } \\
\text { vivos. Comunicación oral y escrita de } \\
\text { resultados. } \\
\text { - Estructura básica de la célula. Uso de } \\
\text { la lupa binocular y de otros medios } \\
\text { tecnológicos para su reconocimiento. } \\
\text { - Aproximación a otras formas de vida: } \\
\text { bacterias, virus, algas y hongos. } \\
\text { - Búsqueda de información sobre los } \\
\text { seres vivos y sus condiciones de vida. } \\
\text { - Sensibilidad por la precisión y el rigor } \\
\text { en la observación de animales y plantas } \\
\text { y en la elaboración de los trabajos } \\
\text { correspondientes. }\end{array}$ & $\begin{array}{l}\text { - Estudio y clasificación de algunos } \\
\text { materiales por sus propiedades } \\
\text { (dureza, solubilidad, estado de } \\
\text { agregación, conductividad } \\
\text { térmica). } \\
\text { - Separación de componentes de } \\
\text { una mezcla mediante: destilación, } \\
\text { filtración, evaporación o } \\
\text { disolución. }\end{array}$ \\
\hline
\end{tabular}

Tabla 1. Contenidos curriculares relacionados con la clasificación de la materia viva e inerte.

También en los criterios de evaluación, se incluye la clasificación de la materia de forma progresiva (ORDEN ECI/3857/2007):

- $\quad$ En primer ciclo (BOE 20 Julio, p. 31501):

- Reconocer y clasificar con criterios elementales los animales y plantas más relevantes de su entorno asi como algunas otras especies conocidas por la información obtenida a través de diversos medios.

- Identificar diferencias en las propiedades elementales de los materiales, relacionando algunas de ellas con sus usos, y reconocer efectos visibles de las fuerzas sobre los objetos, sus componentes y su dirección.

- $\quad$ En segundo ciclo (BOE 20 Julio, p. 31503):

- Identificar y clasificar animales, plantas y rocas, según criterios cientificos.

- $\quad$ En tercer ciclo (BOE 20 Julio, p.31506):

- Diferenciar sustancias de uso cotidiano por su estado de agregación y por su naturaleza química, explicando las características propias de sólidos, líquidos y gases y de algunas sustancias por su naturaleza química.

Por otra parte, en el currículo de Primaria se señalan una serie de orientaciones metodológicas para la enseñanza del área de "Conocimiento del medio" en las que se resalta el papel de las concepciones (ideas) de los alumnos. Hay una clara apuesta por 
una metodología de enseñanza de orientación constructivista, basada en la utilización didáctica de las ideas, experiencias e intereses de los alumnos.

En resumen, el currículo oficial de Primaria propicia una metodología didáctica en las que las concepciones de los alumnos tienen un papel central, y la temática seleccionada (criterios de clasificación de la materia) tiene importancia en la competencia en el conocimiento y la interacción con el mundo físico dado que la clasificación es uno de los procesos científicos básicos que los alumnos de Primaria empiezan a aprender y que los futuros maestros tendrán que aprender a enseñar.

Por todo ello, hemos llevado a cabo un estudio comparativo entre los alumnos de Primaria de los tres cursos finales de ciclo y los futuros maestros, utilizando las tareas de formación de grupos con imágenes de objetos y organismos vivos conocidos, para averiguar qué criterios utilizan en sus clasificaciones y cómo clasifican a partir de criterios dados. Dicho estudio nos ha permitido elaborar una propuesta de niveles de competencia para la clasificación de la materia que puede ser de utilidad en las tareas de evaluación por competencias, tanto de alumnos como de futuros maestros.

\section{Cómo clasifican la materia los alumnos}

De los diferentes marcos teóricos sobre la naturaleza de las concepciones (como estadios de desarrollo cognitivo, como creencias, como teorías, como recursos y como representaciones implícitas) señalados recientemente por García, Mateos y Vilanova (2011), coincidimos en que las concepciones tienen cierta coherencia interna, no son necesariamente explícitas, su devenir puede ser diferente para distintos dominios y su evolución ocurre a través de un proceso mediante el cual las representaciones implícitas se reelaboran en formatos más explícitos y más estables.

Como señala Cubero (2005), los investigadores en Didáctica de las Ciencias se han referido al hecho de que los alumnos desarrollan explicaciones propias sobre el mundo físico-natural con una gran cantidad de términos. En este sentido, la polisemia del lenguaje para designar este "saber" no deja de ser un reflejo de diferentes enfoques sobre la naturaleza, estructura y utilización en el proceso de enseñanza-aprendizaje de los conocimientos de los alumnos. No obstante, podemos decir que estos estudios se enmarcan en un planteamiento general del aprendizaje de orientación constructivista, en el que aprender ciencias es construir modelos para interpretar el mundo, mediante la interacción entre lo que ya sabemos y la nueva información. Diferentes autores (Driver et al., 1989; 1999; Pozo et al., 1991; Oliva, 1999a, 1999b; Posada, 2000; Cubero, 2005; Carrascosa, 2005; Furió et al., 2006) parecen coincidir a lo largo del tiempo en la existencia de una serie de características generales de las concepciones de los alumnos, que podemos resumir en:

a) Son construcciones personales de los alumnos elaboradas de un modo más o menos espontáneo en su interacción con el mundo social y natural, pero compartidas por diferentes grupos; es decir, poseen un cierto carácter transcultural. 
b) Suelen ser incoherentes desde el punto de vista del conocimiento científico y del conocimiento escolar, pero no desde el punto de vista del alumno puesto que le son útiles para explicar y predecir los fenómenos cotidianos. Así, por ejemplo, las ideas que utilizan los alumnos en una determinada situación pueden variar dependiendo del contexto.

c) Son bastante estables y persistentes, a pesar de la enseñanza recibida. Esto es más evidente en la medida en que las ideas transmitidas están más alejadas de la intuición.

d) Guardan, en algunos casos, ciertas similitudes con formulaciones anteriores que se recogen en la historia de las diferentes disciplinas. Tienden a evolucionar con la edad de los alumnos mediante procesos de reestructuración conceptual. También existe al respecto un cierto paralelismo con la historia de la ciencia.

e) Se manifiestan a través del lenguaje oral, escrito y gráfico, pero esencialmente están implícitas en las actividades que los alumnos realizan.

f) No parecen ser ideas aisladas sino que constituyen estructuras, esquemas, marcos, teorías personales o sistemas de ideas, pero con una escasa relación jerárquica.

Por otra parte, la constatación de la importancia de los contenidos específicos en la utilización de las habilidades cognitivas generales por los alumnos es uno de los aspectos más relevantes en la evolución de esta línea de investigación (Vosniadou, 1994). Dicho en otros términos, los procesos no son independientes del contenido al que se aplican. Así, han proliferado los estudios sobre las ideas de los alumnos acerca de los contenidos escolares (la digestión, el calor, el día y la noche, los cambios de estado, etc.) que han sido (y son) una línea de investigación de enorme importancia para la práctica docente $\mathrm{y}$, por lo tanto, para la formación del profesorado.

Como ya se adelantó en la introducción, el tema de la clasificación de la materia, sobre todo en Primaria y en futuros maestros, no es de los más estudiados, no obstante hay algunos estudios que nos han servido de referencia y que a continuación comentamos.

Prieto et al. (2000) relatan una tarea de clasificación del mismo tipo que la que se ha incluido en este estudio. En ella se les propone a los alumnos toda una serie de objetos y seres vivos para que los observaran y manipularan, y a continuación se les pedía que formasen grupos con todos los que creyesen que eran similares y explicaran las razones de tales agrupamientos. Los criterios que los alumnos utilizan espontáneamente para clasificar la materia son:

- Composición, material del que está hecho ese objeto.

- Función, entendida en términos de utilidad.

- Localización, procedencia o lugar donde se encuentra.

- Apariencia, según sus propiedades observables.

- Procesamiento, si es algo natural o fabricado. 
En este estudio se señala que más de la mitad de los alumnos de entre 5 y 9 años utilizan el criterio de la composición, no en términos de si está compuesto de una o varias sustancias (mezcla) sino del material concreto que lo forma. Otro resultado de interés es que el criterio más funcional crece con la edad de los alumnos.

Por lo que respecta al criterio vivo/no vivo, existen investigaciones sobre las ideas de los niños desde los años 20. Piaget (1926) desarrolló uno de los primeros estudios en este campo y mostró que los niños de menos de diez años tenían una visión animista de los objetos inanimados o de los fenómenos físicos. Asimismo, identificó cinco estadios en el concepto de vida de forma que los niños entre 6-7 años consideran vivo aquello que tiene actividad, antes de esta edad no tienen concepto de vida, entre los 8-9 años todo aquello que se mueve, entre los 9-11 las cosas que parecen moverse por sí mismas y a partir de los 11 años sólo se consideran vivos los animales o bien los animales y las plantas.

La investigación también va dirigida a analizar los criterios biológicos que son utilizados para decidir si algo está vivo. Al aumentar la edad de los niños se va poniendo más énfasis en los procesos biológicos y menos en la utilidad para las personas (Tamir et al., 1981). Es común identificar ser vivo solo con animal y asociarlo fundamentalmente al movimiento (Lucas et al., 1979; Brumby, 1982), los vegetales son considerados menos vivos que los animales (Caballer y Giménez, 1992; Mondelo, García y Martínez, 1994), los criterios de comportamiento son utilizados para definir ser vivo por encima de los fisiológicos o morfológicos, (Brumby, 1982; De Manuel y Grau, 1996) de forma que los atributos más comunes entre alumnos de 10-15 años son: comer/beber, moverse/andar, respirar y crecer.

En alumnos universitarios encontramos algunas discrepancias. Así Brumby (1982) observa que el movimiento, seguido del crecimiento y de otras funciones vitales, es uno de los criterios más utilizados para determinar si un ser está vivo. Sin embargo, Mondelo, Martínez y García (1998) encuentran que predominan las características fisiológicas sobre los criterios estructurales; y dentro de éstas es la alimentación/nutrición la más señalada; si bien ambos estudios coinciden en señalar la dificultad que tienen los estudiantes para reconocer la célula como unidad de vida, al igual que lo hacen Caballer y Giménez (1992).

Finalmente, el hecho de que se clasifique correctamente como vivo o no vivo no indica un control biológico de las implicaciones del concepto de vida (Looft, 1974), pocos alumnos utilizan una combinación de atributos, sino que se centran en uno crítico, que no tiene que ser siempre el mismo para justificar su clasificación. Esta inconsistencia de los alumnos en la generalización del concepto de vida también ha sido señalada por Tamir et al. (1981), Carey (1985) y Strommen (1995) recalcando que los alumnos centran su atención en aspectos particulares y directamente observables.

Por otra parte, la clasificación de la materia ha tenido una especial presencia en el informe de resultados de la evaluación general de diagnóstico 2009 realizada en $4^{\circ}$ de Primaria (http://www.educacion.gob.es/ievaluacion/publicaciones/evaluaciondiagnostico.html). Aunque todas las tareas propuestas se refieren a seres vivos, es importante destacar que el promedio de los porcentajes de alumnos de cuarto de 
Educación Primaria en los niveles más bajos de competencia científica (nivel menor que 1 y nivel 1: los alumnos tienen capacidad para identificar y clasificar animales relevantes de su entorno con criterios elementales) es el 17\%, mientras que el promedio de los porcentajes de alumnos en el nivel más alto de competencia científica (nivel 5: los alumnos son capaces de identificar y reconocer las peculiaridades de los grupos más importantes de seres vivos e identificar sus principales funciones) es el $8 \%$.

Por último, señalar que estas tareas tienen un formato interesante para apreciar cómo los alumnos aplican los criterios de clasificación a los casos concretos, aunque no tenemos información de su manera de entender el criterio utilizado, y tampoco nos suministran datos sobre los criterios que espontáneamente utilizarían los alumnos para resolver las tareas de clasificación, ese es precisamente nuestro interés.

\section{Diseño de la investigación}

Los problemas que pretendemos abordar en este estudio pueden formularse como sigue:

¿Qué criterios utilizan los alumnos de Primaria y los futuros maestros de la muestra para clasificar la materia? y ¿cómo utilizan los criterios básicos (vivo/no vivo) de clasificación de la materia?

La revisión de los estudios sobre concepciones de los alumnos y nuestra propia experiencia docente nos ha permitido formular algunas posibles hipótesis. En primer lugar, esperamos encontrar una diversidad de respuestas en las diferentes muestras, por ser esta una de las características más relevantes de las concepciones de los alumnos (Cubero, 2005), aunque también esperamos apreciar una evolución a lo largo de los tres ciclos de la Primaria y con respecto a los futuros maestros. En segundo lugar, esperamos que los alumnos de Primaria utilicen criterios basados en la utilidad y en las propiedades observables, como señala Prieto et al., (2000), que identifiquen ser vivo con animal y que lo asocien fundamentalmente al movimiento (Lucas et al., 1979) en los tres ciclos de Primaria. Igualmente esperamos constatar que los alumnos de segundo y tercer ciclo utilizan criterios de comportamiento (se mueve, come, respira...) en mayor medida que criterios morfológicos, estructurales o fisiológicos, como han mostrado las investigaciones de Brumby (1982) y De Manuel (1994). Y por último, en alumnos universitarios esperamos un predominio de las características fisiológicas sobre las estructurales (Mondelo, et al., 1998).

Así pues, los objetivos de este estudio son:

1) Describir y analizar los criterios que los alumnos de Primaria y los futuros maestros utilizan para clasificar la materia.

2) Comparar los criterios para clasificar la materia que utilizan ambas muestras.

3) Describir y analizar la utilización que hacen los alumnos de Primaria y los futuros maestros de los criterios básicos de clasificación de la materia (vivo /no vivo). 
4) Comparar los criterios básicos para clasificar la materia (vivo /no vivo) que utilizan ambas muestras.

5) Proponer niveles de competencia en la clasificación de la materia para la Educación Primaria.

Este último objetivo está fundamentado por un lado, en lo que Astolfi (2002) denomina niveles de formulación que, a modo de hipótesis, categorizan las concepciones de los alumnos en un gradiente de progresiva complejidad y abstracción. Y, por otro lado, en lo que para este autor es el núcleo duro o resistente de las concepciones de los alumnos. Es decir, los obstáculos que han de superar en el proceso de construcción conceptual (Astolfi, 1999). La detección de los niveles de formulación y obstáculos, junto con las actividades de enseñanza-aprendizaje que pueden facilitar su superación, nos permitirá proponer niveles de competencia en la clasificación de la materia.

\section{Muestra y contexto}

El estudio se ha realizado con alumnos del Colegio Público Trabenco de Leganés (Madrid) (www.trabenco.com). Se trata de un centro escolar cuyos principios de identidad son: Libre expresión y creatividad, Actitud crítica, Responsabilidad y solidaridad, Valoración de la diversidad, Gestión democrática y participativa, y Aprender investigando. En el área de Conocimiento del Medio se apuesta claramente por una metodología didáctica basada en la investigación escolar (Inquiry-Based Science Education) tal y como se recomienda en los informes sobre la educación científica (véase el informe Rocard, 2007 que puede consultarse en http://blog.educastur.es/bitacorafyq/files/2008/02/informe-rocard.pdf). Así pues se trabaja por proyectos, en los que alumnos de todos los niveles toman decisiones sobre el tema a trabajar, las preguntas a resolver, los recursos a utilizar y los lenguajes a través de los cuales plasmar lo aprendido. De esta forma participan en su propio proceso de aprendizaje y aprenden a aprender.

En este contexto, después de presentar a las maestras de $2^{\circ}, 4^{\circ}$ y $6^{\circ}$ de Primaria el estudio que queríamos realizar, pudimos acceder a las aulas y proponer las tareas de clasificación a estos alumnos. Finalmente, la muestra la conformaron un total de 55 alumnos (20 de los 22 alumnos de $2^{\circ}$, 18 de $\operatorname{los} 22$ alumnos de $4^{\circ}$ y 17 de los 18 alumnos de $6^{\circ}$ de Primaria). Ninguno de estos alumnos había tratado durante el curso la clasificación de la materia.

Por otra parte, la muestra de futuros maestros está formada por 55 estudiantes de tercer curso del Grado de Maestro de Primaria en la Facultad de Educación de la Universidad Complutense de Madrid, que al empezar el curso 2011-2012 asistían a la clase de una asignatura del departamento de Didáctica de las Ciencias Experimentales.

Dado que se trata en ambos casos de muestras reducidas, el estudio que se presenta tiene un carácter de "estudio piloto" que servirá para revisar el contenido de las tareas 
de clasificación y de las entrevistas que se pretenden realizar en un futuro para profundizar en los criterios utilizados por los alumnos.

\section{Obtención y análisis de los datos}

Teniendo en cuenta el tipo de tareas que en los estudios revisados se utilizan para el estudio de las concepciones de los alumnos, se propusieron dos tareas: una de clasificación de la materia y otra de aplicación de criterios básicos de clasificación (vivo / no vivo). En ambos casos se propone agrupar 12 imágenes diferentes, solicitando siempre la justificación de sus agrupaciones (Figuras 1 y 2). Las imágenes se seleccionaron con el criterio de que fuesen muy conocidas por los alumnos, buscando una proporción similar de materia viva y de materia inerte y de que los organismos u objetos representados fueran susceptibles de generar cierto conflicto cognitivo en los alumnos con el fin de que movilizasen y explicitasen sus ideas.

Haz dos grupos con lo que ves en las imágenes siguientes:

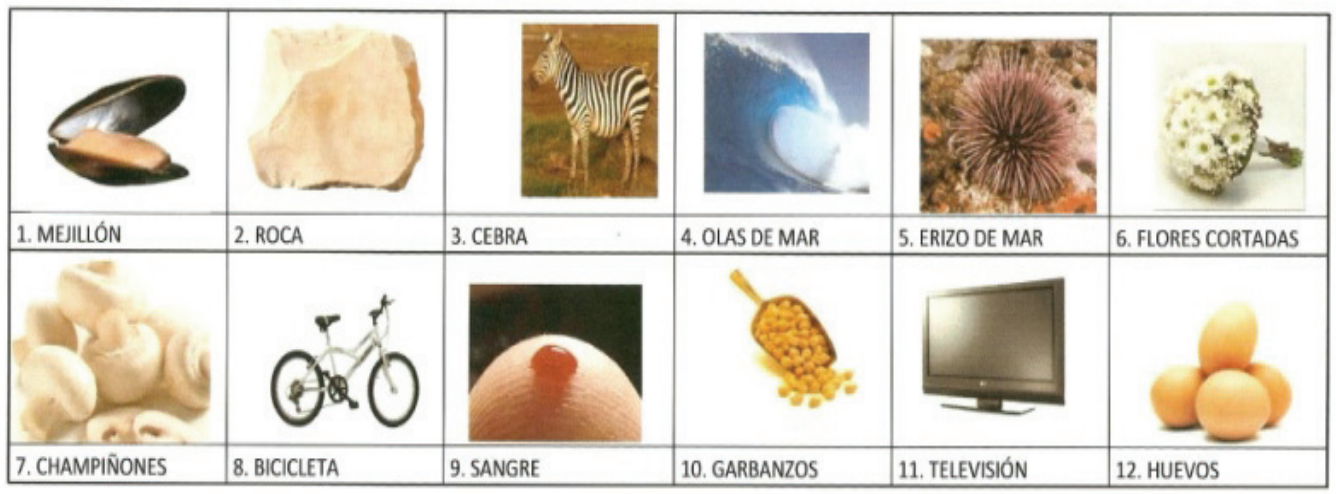

Figura 1: Imágenes seleccionadas para la tarea de clasificación de la materia. 
Haz dos grupos, uno con lo vivo y otro con lo que no está vivo y que nunca ha tenido vida:

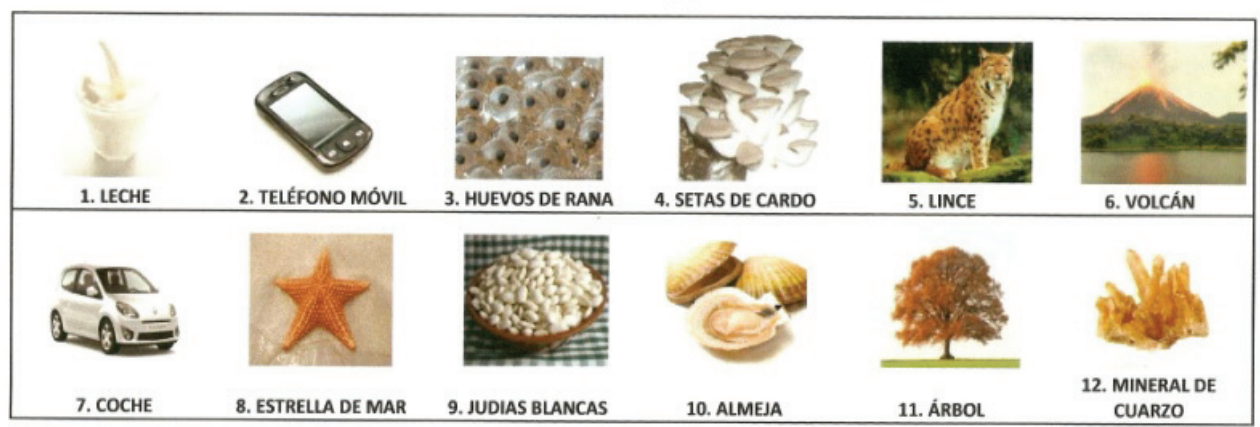

Figura 2. Imágenes seleccionadas para la tarea de aplicación del criterio vivo/no vivo.

Al ser una tarea de respuesta abierta, utilizamos el análisis de contenido categorial definido por Bardin (1986). En primer lugar, se procedió a vaciar los datos (respuestas a la tarea) en un sistema de tablas que facilitara el análisis posterior. Teniendo en cuenta los resultados de los estudios sobre esta temática, se procedió a buscar grupos de respuestas comunes y así inferir el tipo de criterios de clasificación que utilizan. Dado el tamaño de la muestra solo se han utilizado estadísticos descriptivos (frecuencia y porcentaje), lo que nos permite un primer acercamiento a los diferentes criterios que utilizan los sujetos.

\section{Resultados}

\section{Criterios de clasificación de la materia}

En la Tabla 2 se indica el análisis de las respuestas a la tarea de clasificar 12 imágenes de materia (mejillón, roca, cebra, olas de mar, erizo de mar, flores cortadas, champiñones, bicicleta, sangre, garbanzos, televisión y huevos) en dos grupos, sin indicarles el criterio que debían utilizar. 


\begin{tabular}{|c|c|c|c|c|c|}
\hline \multicolumn{2}{|c|}{ CRITERIOS CLASIFICACIÓN LA MATERIA } & $\begin{array}{c}2^{\circ} \\
\text { Primaria }\end{array}$ & $\begin{array}{c}4^{\circ} \\
\text { Primaria } \\
\end{array}$ & $\begin{array}{c}6^{\circ} \\
\text { Primaria }\end{array}$ & $\begin{array}{l}\text { Grado } \\
\text { Maestro }\end{array}$ \\
\hline \multirow{7}{*}{$\begin{array}{l}\text { Criterios } \\
\text { Generales }\end{array}$} & Función (alimento...) & 32.7 & 55.6 & 26.5 & 7.3 \\
\hline & Localización (marinos, terrestres...) & 14.3 & 13.9 & 0 & 1.8 \\
\hline & Procesamiento (natural, artificial,...) & 6.1 & 13.9 & 14.7 & 25.4 \\
\hline & Propiedades observables (color,...) & 4.1 & 0 & 0 & 0 \\
\hline & Frecuencia de aparición $(\operatorname{raras}, \ldots)$ & 0 & 0 & 14.7 & 0 \\
\hline & Composición (materia inorgánica...) & 0 & 0 & 0 & 3.6 \\
\hline & Otros & 0 & 0 & 8.8 & 0 \\
\hline \multirow{5}{*}{$\begin{array}{c}\text { Criterios } \\
\text { específicos }\end{array}$} & Vivo /no vivo & 4.1 & 13.9 & 29.4 & 29.1 \\
\hline & Vivo, parte o producto /no vivo & 0 & 0 & 0 & 23.6 \\
\hline & Animales/no animales & 0 & 0 & 0 & 3.6 \\
\hline & Estructurales (células) & 0 & 0 & 0 & 1.8 \\
\hline & Movimiento autónomo & 0 & 0 & 0 & 3.6 \\
\hline $\begin{array}{l}\text { Criterios } \\
\text { Subjetivos }\end{array}$ & Relación causa-efecto & 32.7 & 0 & 0 & 0 \\
\hline \multicolumn{2}{|c|}{ Sin indicar criterios } & 4.1 & 2.8 & 5.9 & 0 \\
\hline \multicolumn{2}{|c|}{ No contesta } & 2 & 0 & 0 & 0 \\
\hline
\end{tabular}

Tabla 2. Porcentajes en los criterios de clasificación de la materia.

Los alumnos de $2^{\circ}$ Primaria tienen gran dificultad para establecer un criterio dicotómico, y son sólo dos alumnos los que clasifican atendiendo a una dicotomía del tipo: "es comida /no es comida", los demás clasifican estableciendo una combinación de criterios. Por ejemplo, utilizan "se come" y formulan un segundo criterio, o a veces más, para agrupar lo que se les ha quedado fuera de la primera agrupación. Hay dos criterios que destacan y aparecen con el mismo peso (32.7\%), uno es un criterio general de funcionalidad: "ser o no comida", y el otro un criterio subjetivo de causaefecto, que suele ser elegido como la segunda o tercera opción de agrupamiento. Un ejemplo de este tipo sería: "te caes de la bicicleta y te haces sangre con la roca". El criterio general Localización "marinos/terrestres" aparece en tercer lugar con un $14.3 \%$. En este curso encontramos 11 alumnos que no clasifican todas las imágenes, de forma que 6 alumnos no clasifican la televisión; la cebra, las flores cortadas y la bicicleta no son clasificadas por 5 alumnos respectivamente y por último, los garbanzos por 4 alumnos. Otra imagen que hay que destacar es la sangre porque para casi el 50\% de los alumnos ha de ir relacionada con algo que la "cause" como puede ser la caída de una bicicleta o el golpe con una roca. 
En $4^{\circ}$ curso ya se observa una gran coherencia a la hora de establecer un criterio de clasificación, de forma que de los 18 alumnos, 15 establecen criterios dicotómicos: "se come/no se come" (función), "marino/terrestre" (localización), "natural/artificial" (procedencia) y "vivo /inerte". Los tres primeros son criterios generales y este último específico. Destaca la funcionalidad como el más utilizado (55.6\%), y los otros tres son utilizados en la misma proporción (13.9\%). Disminuye el número de alumnos que no logran clasificar la totalidad de las imágenes (6 alumnos frente a 10 del grupo de $2^{\circ}$ ), siendo la bicicleta y la sangre las que más confusiones plantean. A diferencia de los alumnos del primer ciclo, éstos ya no establecen criterios subjetivos como los de causaefecto, tan destacables en los más pequeños.

En $6^{\circ}$ curso el criterio más utilizado (29.4\%) es el criterio específico "vivo/ no vivo", lo que le diferencia de los dos anteriores ciclos, y disminuye con respecto a $4^{\circ}$ curso el criterio "se come/no se come/ (26.5\%), aunque sigue siendo el segundo en importancia. Ningún alumno hace referencia a la localización, y el criterio "natural/artificial" se mantiene en proporción similar al grupo de $4^{\circ}$ curso. En este grupo toma importancia un criterio general como es el de frecuencia de aparición (5 alumnos aluden a la cotidianeidad de las imágenes), y sin embargo este criterio no fue utilizado por ningún alumno de los ciclos anteriores. La totalidad de las imágenes son clasificadas por todos los alumnos pero la sangre es considerada como ser vivo por tres alumnos.

En los estudiantes de Grado todos, excepto uno, establecen criterios dicotómicos y clasifican la totalidad de las imágenes. El $38.1 \%$ lo hace atendiendo a criterios generales, siendo el mayoritario el procesamiento (naturales, artificiales, manipulados) con un 25.4\%, seguido de la función (alimento) con un $7.3 \%$. El $61.8 \%$ de los estudiantes clasifica atendiendo a criterios específicos, de forma mayoritaria hay un $29.1 \%$ que establecen la dicotomía "está vivo o es un ser vivo / no está vivo", en un $23.6 \%$ de los casos los estudiantes amplían esta clasificación, de forma que incluyen lo vivo y todo aquello relacionado con lo vivo, o bien por ser un producto de ello o por ser parte constituyente. Sorprende que sólo un $1.8 \%$ clasifica atendiendo a la estructura celular o no de lo clasificado.

En el Gráfico 1 podemos apreciar como varían los porcentajes de cada uno de los criterios utilizados según los grupos. 


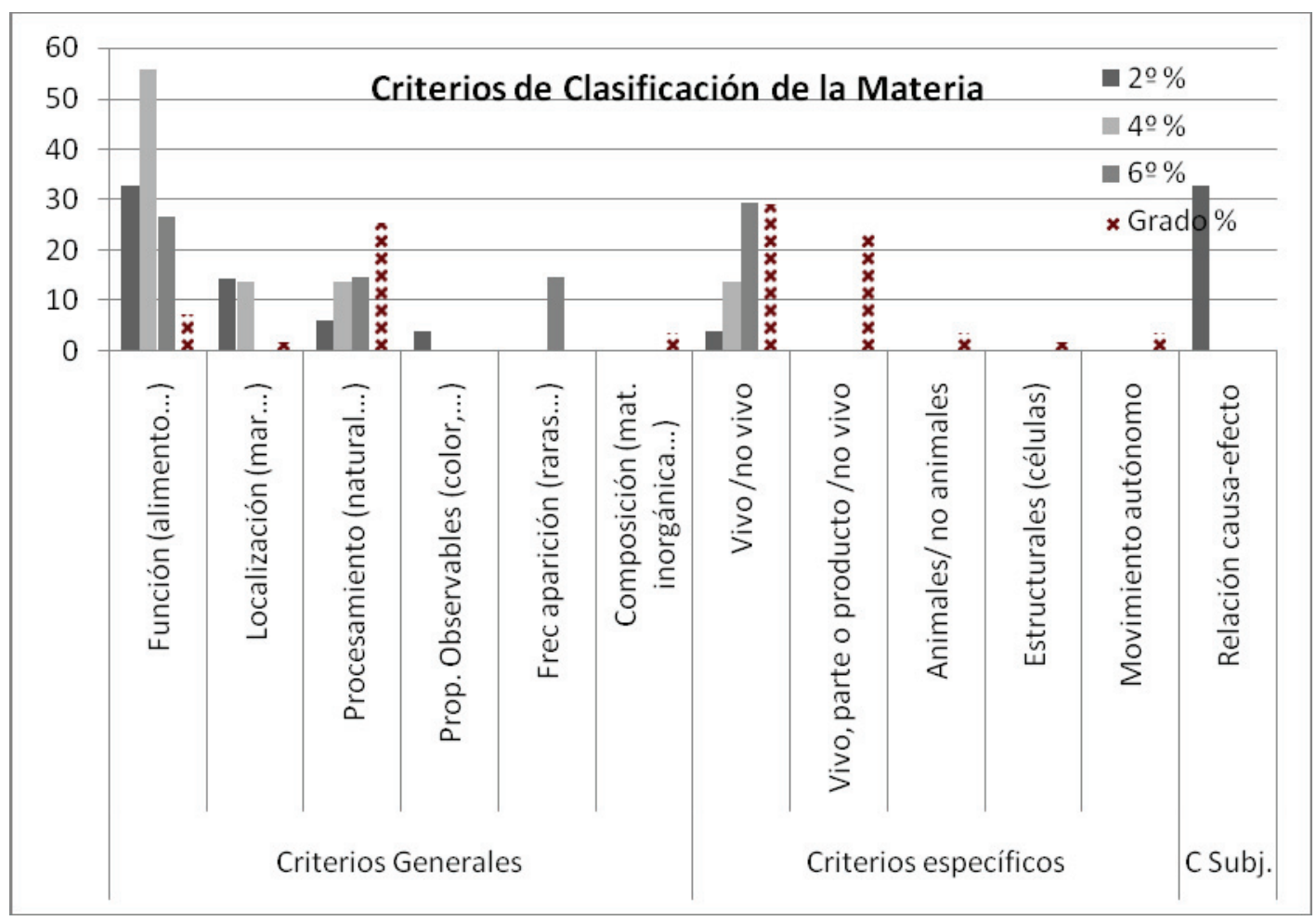

Gráfico 1. Porcentajes por grupos de los principales criterios de clasificación de la materia.

\section{Aplicación del criterio vivo/no vivo para clasificar la materia}

En las Tablas 3 y 4 se indican las respuestas a la tarea de clasificar 12 imágenes de materia (leche, teléfono móvil, huevos de rana, setas de cardo, lince, volcán, coche, estrella de mar, judias blancas, almeja, árbol y cuarzo) en dos grupos: uno el de lo vivo y otro con lo que no está ni nunca ha estado vivo; es decir, aplicando el criterio "vivo / no vivo". Estas imágenes son equivalentes pero no iguales a las de la anterior tarea y han sido colocadas en distinto orden. 


\begin{tabular}{|l|c|c|c|c|}
\hline \multirow{2}{*}{$\begin{array}{c}\text { IMÁGENES DE } \\
\text { MATERIA INERTE }\end{array}$} & \multicolumn{4}{|c|}{ Porcentaje de alumnos que la clasifican como MATERIA VIVA } \\
\cline { 2 - 5 } & $2^{\circ}$ Primaria & $4^{\circ}$ Primaria & $6^{\circ}$ Primaria & Grado Maestro \\
\hline Leche & 0 & 11 & 18 & 18.2 \\
\hline Teléfono móvil & 10 & 5.6 & 0 & 0 \\
\hline Volcán & 45 & 39 & 29 & 29.1 \\
\hline Coche & 15 & 5.6 & 0 & 1.8 \\
\hline Cuarzo & 10 & 0 & 0 & 7.3 \\
\hline
\end{tabular}

Tabla 3. Porcentaje de alumnos que clasifican como seres vivos las imágenes de materia inerte.

\begin{tabular}{|l|c|c|c|c|}
\hline \multirow{2}{*}{$\begin{array}{c}\text { IMÁGENES DE } \\
\text { MATERIA VIVA }\end{array}$} & \multicolumn{4}{|c|}{ Porcentaje de alumnos que las clasifican como MATERIA INERTE } \\
\cline { 2 - 5 } & $2^{\text {o }}$ Primaria & $4^{\text {o }}$ Primaria & $6^{\circ}$ Primaria & Grado Maestro \\
\hline Huevos de rana & 15 & 0 & 12 & 0 \\
\hline Setas de cardo & 20 & 5.6 & 0 & 0 \\
\hline Lince & 0 & 0 & 0 & 0 \\
\hline Estrella de mar & 10 & 0 & 0 & 0 \\
\hline Judías blancas & 90 & 39 & 59 & 52 \\
\hline Almejas & 10 & 11 & 5.9 & 1.8 \\
\hline Árbol & 10 & 0 & 0 & 3.6 \\
\hline
\end{tabular}

Tabla 4. Porcentaje de alumnos que clasifican como materia inerte las imágenes de materia viva.

Como puede observarse sólo una imagen es clasificada correctamente por todos los alumnos y en todos los niveles: el lince, seguramente debido a que se corresponde con el estereotipo de animal que suelen tener los niños (mamífero, cuadrúpedo, con pelo...etc.) y al que éstos consideran "más vivo" que a una planta. Por el contrario, son varias las imágenes que han suscitado mayor dificultad y error en su clasificación tanto en los alumnos de Primaria como en los universitarios. Estas son: las judías blancas, el volcán, la leche y las almejas. Como ya pudimos constatar con el análisis de la tarea anterior, vuelven a ser las semillas, en este caso las judías blancas, las que mayor porcentaje de error presentan, en el caso de los alumnos de primer ciclo de Primaria. Un $90 \%$ consideran que no son seres vivos, el porcentaje disminuye considerablemente en el segundo ciclo (sólo un 39\% las consideran inertes), para aumentar en el tercer ciclo hasta un 59\%, y no deja de sorprender que en los estudiantes de Grado este porcentaje sea muy similar al de los alumnos de $6^{\circ}$ de Primaria con un $52 \%$. Con la imagen del volcán sucede algo parecido, va disminuyendo el error al aumentar de ciclo en Primaria, pasando de un $45 \%$ de alumnos que consideran al volcán como ser vivo en el primer ciclo, a un $39 \%$ en el segundo ciclo y a un $29 \%$ en el tercero; siendo este último porcentaje el mismo que encontramos en los estudiantes de Grado. 
Como era de esperar, en general las mayores dificultades las encontramos en los alumnos más pequeños, para ir disminuyendo al avanzar en las etapas; sin embargo hay algunas imágenes que siguen generando conflicto, incluso en los estudiantes de Grado, como son: la leche, el coche, el cuarzo y el árbol. La leche es la única que genera más dificultad según avanzamos en edad, teniendo el mismo porcentaje de error en su clasificación (18\%) tanto en alumnos de $6^{\circ}$ de Primaria como en estudiantes de Grado. El mineral de cuarzo, que es correctamente clasificado por los alumnos de $4^{\circ}$ y $6^{\circ}$ de Primaria, no lo es por los de Grado con un 7.3\% de estudiantes que lo consideran como vivo.

\section{Atributos asociados a los seres vivos}

En la Tabla 5 se detallan los atributos que han manejado tanto los alumnos de Primaria como los estudiantes de Grado para fundamentar sus decisiones. Hemos de indicar que en ellas no hemos incluido aquellas respuestas que no aportan ninguna información, como es el caso de "porque son seres vivos"; y se han incluido todos los atributos que han señalado cada uno de los alumnos. De esta forma el porcentaje hace referencia al número de veces que ha sido nombrado el atributo sobre la totalidad de los mencionados en cada grupo.

\begin{tabular}{|l|c|c|c|c|}
\hline \multicolumn{1}{|c|}{ ATRIBUTOS DE LO VIVO } & $2^{0}$ Primaria & $4^{0}$ Primaria & $6^{0}$ Primaria & $\begin{array}{c}\text { Grado } \\
\text { Maestro }\end{array}$ \\
\hline Movimiento & 35 & 33.3 & 41.2 & \\
\hline Funciones vitales (ciclo vital) & & & 11.8 & 14.5 \\
\hline Nacen & 10 & 5.6 & 5.9 & 9.1 \\
\hline Crecen & 5 & 27.8 & 17.6 & 10.9 \\
\hline Se reproducen & & & & 16.4 \\
\hline Se nutren (alimentan) & 5 & 5.6 & 11.8 & 7.3 \\
\hline Mueren & & 5.6 & 17.6 & 10.9 \\
\hline Respiran & 5 & 16.7 & & 10.9 \\
\hline Células (composición) & 5 & & & 3.6 \\
\hline Materia orgánica (composición) & & & & 1.8 \\
\hline Sienten & 5 & 5.6 & & \\
\hline Se comunican & & 5.6 & 5.9 & \\
\hline Piensan & & & 5.9 & \\
\hline Intencionalidad & & 5.6 & & \\
\hline Germinan & & 16.7 & & \\
\hline Se adaptan & & & & 1.8 \\
\hline Órganos (animales, vegetales) & & 16.7 & 29.4 & \\
\hline Tienen hormonas (reaccionan) & & & 5.9 & \\
\hline
\end{tabular}




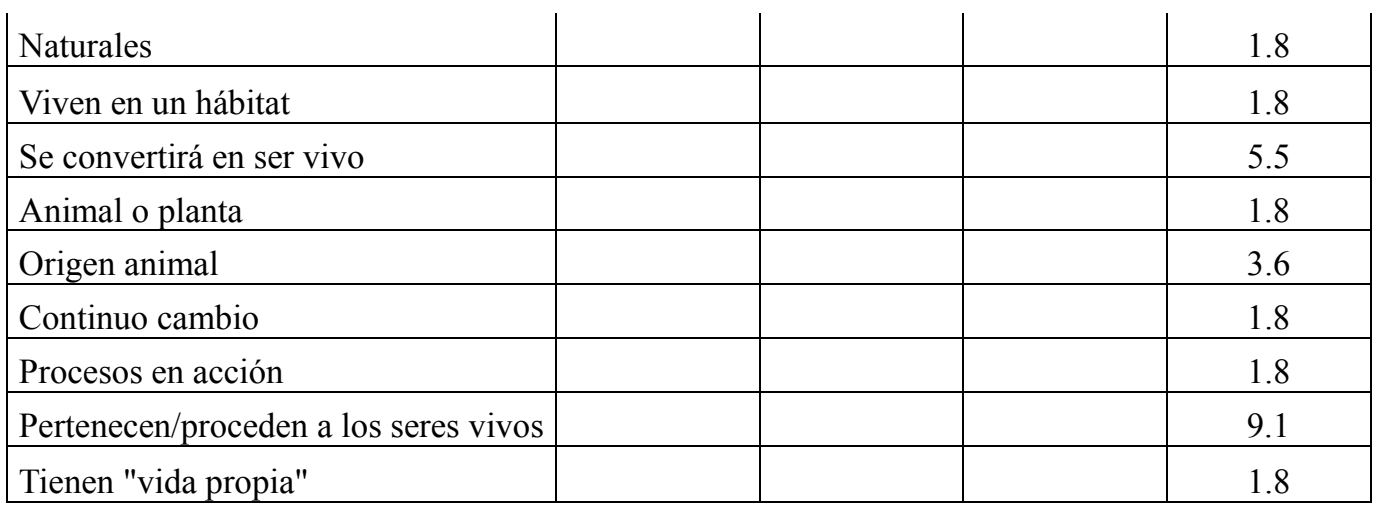

Tabla 5. Porcentajes en los criterios atribuidos a los seres vivos por los alumnos de Educación Primaria y de Grado.

Los alumnos de Primaria encuentran bastantes dificultades para explicitar sus criterios, especialmente los alumnos del primer ciclo. Además, la mayoría sólo menciona un atributo para resolver la tarea, siendo el atributo movimiento para caracterizar a "lo vivo" el que destaca sobre el resto, con un porcentaje bastante estable a lo largo de toda la etapa (35\% en el primer ciclo, $33.3 \%$ en el segundo y $41.2 \%$ en el tercero). Algunas de las funciones vitales son las que se señalan en segundo lugar. En el primer ciclo destaca el atributo "nacen" con un $10 \%$, y en el segundo ciclo "crecen" con un $27.6 \%$. Los criterios estructurales aparecen en el segundo y tercer ciclo donde se menciona la posesión de órganos específicos (de animales o vegetales) en un porcentaje considerable, de forma que en el tercer ciclo es el segundo atributo mencionado con un $29.4 \%$. La germinación como atributo sólo se menciona por los alumnos de segundo ciclo con un $16.7 \%$, lo que evidencia la dificultad que tienen para generalizar características comunes a todos los seres vivos, especialmente a plantas y animales. En el tercer ciclo los alumnos utilizan por primera vez el término "funciones vitales", siendo las más utilizadas "crecen" y "mueren" con un $17.6 \%$ cada una; y sorprende que sea el único grupo que no menciona la "respiración".

En estudiantes universitarios son las funciones vitales el atributo más señalado (14.5\%) y ninguno menciona el movimiento como característica de los seres vivos. La mayoría responden reproduciendo casi literalmente la "cantinela" que han aprendido a lo largo de su vida académica: "nacen, crecen, se reproducen y mueren", con distintas variaciones, de forma que el atributo más señalado dentro de estas funciones es la reproducción con un $16.4 \%$ y el que menos se menciona es la nutrición con tan solo un $7.3 \%$. Los restantes (nacen, crecen, respiran y mueren) aparecen en una proporción similar en torno al $10 \%$. A diferencia de los alumnos de Primaria ninguno hace alusión a la posesión de órganos específicos de los seres vivos; y sólo dos estudiantes mencionan la estructura celular. Los atributos "se convertirán en ser vivo" con un 5.5\% $\mathrm{y}$ "pertenecen o proceden de los seres vivos" con un $9.1 \%$ indican que no todo lo que 
han clasificado como ser vivo es considerado realmente un ser vivo, y muestra la dificultad que tienen todavía estos estudiantes para caracterizar lo vivo y conocer sus límites. Aunque en este grupo no aparece de forma específica el atributo movimiento, sí aparecen otros como "continuo cambio" ó "procesos en acción", que de una forma indirecta aluden al movimiento o a una especie de ciclo vital (aquí han incluido al volcán), pero el porcentaje es mínimo. Vemos que la variabilidad de criterios ha ido aumentando según aumenta la edad de los alumnos.

\section{Atributos asociados a la materia inerte}

En la Tabla 6 se muestran los atributos que han utilizado los alumnos para caracterizar la materia inerte.

\begin{tabular}{|c|c|c|c|c|}
\hline ATRIBUTOS DE LO INERTE & $2^{\circ}$ Primaria & $4^{\circ}$ Primaria & $6^{\circ}$ Primaria & $\begin{array}{c}\text { Grado } \\
\text { Maestro } \\
\end{array}$ \\
\hline Sin movimiento & 20 & 22.2 & 35.3 & \\
\hline Artificial (creado por el hombre) & 10 & 55.6 & 35.3 & 25.5 \\
\hline No autónomos & & & & 1.8 \\
\hline Sin funciones vitales (ciclo) & & & 5.9 & 14.5 \\
\hline No nace & 5 & 5.6 & 5.9 & 3.6 \\
\hline No se alimenta & 5 & & 11.8 & 3.6 \\
\hline No crecen & & 11.1 & 11.8 & 5.5 \\
\hline No respira & & 11.1 & 11.8 & 1.8 \\
\hline No siente & 5 & 5.6 & & \\
\hline No se reproducen & & & 5.9 & 7.3 \\
\hline No mueren & & & 5.9 & 5.5 \\
\hline No tienen cuerpo & 5 & & & \\
\hline Sin órganos & & 16.7 & 11.8 & \\
\hline Sin metabolismo & & & 5.9 & \\
\hline Sin células & & & & 1.8 \\
\hline Materia inorgánica (composición) & & & & 1.8 \\
\hline No se comunican & & 5.6 & 5.9 & \\
\hline No piensan & & & 5.9 & \\
\hline Sin inteligencia & & & 5.9 & \\
\hline Inanimado & & & & 1.8 \\
\hline No cambian & & & 5.9 & 1.8 \\
\hline
\end{tabular}

Tabla 6. Porcentajes en los criterios atribuidos a la materia inerte por los alumnos de Educación Primaria y de Grado. 
Para los alumnos de Primaria los dos atributos más utilizados son la ausencia de movimiento y la artificialidad (creados por el hombre). En el caso del primer ciclo es la ausencia de movimiento el mayoritario (20\%), en el segundo ciclo es el ser artificial con un $55.6 \%$ el que destaca por encima de la ausencia de movimiento con un $22.2 \%$, y en el tercer ciclo aparecen con el mismo peso (35.3\%) ambos atributos. Si exceptuamos el atributo "artificial", la caracterización de lo no vivo se hace fundamentalmente aludiendo a aquello que no hacen o a aquello que no poseen las imágenes a clasificar.

En el caso de los 55 estudiantes de Grado, sólo 16 aplicaron correctamente el criterio vivo / no vivo y de ellos 8 no supieron mencionar ningún atributo válido para fundamentar sus decisiones. Se detectaron un $34.5 \%$ de respuestas no válidas, del tipo "porque no son seres vivos", y un 5.5\% que no explicitó por escrito los atributos utilizados en la clasificación. Entre los que dieron una respuesta válida, el atributo más señalado ha sido ser "artificial" con un $25.5 \%$ de los casos, y a diferencia de los alumnos de primaria, la ausencia de movimiento no ha sido relevante. En segundo lugar, un $14.5 \%$ de estudiantes señala la ausencia de las funciones vitales como característica de lo no vivo.

\section{Conclusiones}

Después de describir, analizar, comparar y discutir los resultados de estas tareas de clasificación, estamos en situación de tratar de responder a los interrogantes de este estudio, viendo cómo las hipótesis inicialmente formuladas al respecto se han ido enriqueciendo con los resultados, en el siguiente sentido:

- Se esperaba encontrar una diversidad de respuestas y efectivamente lo hemos detectado pero además sorprende que disminuya considerablemente el número de criterios en el segundo ciclo para aumentar en el tercero.

- Se esperaba detectar una evolución en los criterios utilizados a lo largo de los tres ciclos de la Primaria. Sin embargo, la complejidad de los criterios utilizados no evoluciona progresivamente. Es patente en el paso del primer a segundo ciclo y parece ralentizarse del segundo al tercero. Lo mismo sucede al pasar al nivel universitario, manteniéndose algunos porcentajes de respuesta similares e incluso idénticos a los que presentan los alumnos de $6^{\circ}$ de Primaria. Esto se hace especialmente patente en el caso de las semillas (garbanzos, judías), que no son consideradas un ser vivo por algo más del $50 \%$ de los alumnos tanto en $6^{\circ}$ como en universitarios. Asimismo, el porcentaje de alumnos que consideran vivo al volcán es exactamente el mismo para estos dos grupos (29\%). En algunos casos, parece incluso incrementarse la dificultad que tienen los estudiantes universitarios sobre los alumnos de segundo y tercer ciclo de Primaria. Así encontramos que un 7.3\% de los estudiantes de Grado clasifican como ser vivo el mineral de cuarzo, cuando fue perfectamente clasificado por los alumnos de $4^{\circ}$ y $6^{\circ}$ de Primaria. También la leche presenta una dificultad que se incrementa a lo largo de los ciclos y que se iguala en los alumnos de $6^{\circ}$ y de Grado con un $18 \%$ que indican que están ante un ser vivo. 
- Se esperaba que los criterios espontáneos basados en la utilidad y en las propiedades observables fueran mayoritarios en la muestra de alumnos de Primaria. Podemos señalar que estos criterios se concretan en "la comida", siendo el más señalado y el que aumenta considerablemente a lo largo de la etapa de Primaria. También están presentes, aunque en una proporción menor (7.3\%) en los estudiantes de Grado. Además se han detectado otros criterios fundamentales para clasificar la materia como son los subjetivos, especialmente relevantes en el primer ciclo, y criterios específicos para la materia viva en el segundo y el tercer ciclo (este será el criterio mayoritario en estudiantes de Grado).

- Se esperaba que en la aplicación del criterio vivo/ no vivo identificaran ser vivo con animal y con movimiento. Efectivamente los alumnos asocian lo vivo con el movimiento a lo largo de toda la etapa de Primaria. Sin embargo, sorprende que no es señalado por los estudiantes de Grado. En el caso de lo no vivo, los alumnos de segundo ciclo consideran el carácter artificial de forma mayoritaria frente al no movimiento, al igual que los estudiantes de Grado. Sin embargo en el tercer ciclo de Primaria, volverá a ser la ausencia de movimiento, en el mismo porcentaje que la artificialidad, lo que caracterice a lo no vivo. Como en el apartado anterior, se constata que en todos los ciclos lo vegetal se considera menos vivo que lo animal.

- Se esperaba que los alumnos de segundo y tercer ciclo utilizaran criterios de comportamiento (se mueve, come, respira...) en mayor medida que criterios morfológicos, estructurales o fisiológicos para clasificar. Esto se confirma en los alumnos más pequeños, sin embargo, en el tercer ciclo los criterios estructurales adquieren mucha relevancia, si bien es cierto que se ciñen a lo macroscópico, a lo que se ve a simple vista, y distinguen claramente entre estructuras vegetales y animales, evidenciando que son incapaces de utilizar criterios generales que caractericen a los seres vivos, y excepto algún alumno de $6^{\circ}$, las referencias a la estructura celular de la materia viva es prácticamente inexistente.

- Se esperaba encontrar un predominio de las características fisiológicas sobre las estructurales en los estudiantes de Grado, hecho que se ha confirmado. No han hecho ninguna mención al movimiento, y el crecimiento tampoco ha sido un atributo que destacase sobre el resto. Los resultados parecen indicar que los estudiantes llegan a la universidad sin haber adquirido un aprendizaje significativo del concepto "vida" sino más bien con un aprendizaje memorístico de las características de los seres vivos. También se observa la dificultad que tienen para aplicar los conceptos teóricos adquiridos a lo largo de la educación obligatoria a la resolución de la tarea propuesta, mostrando en muchos casos un conocimiento ligado al contexto. Esto puede apreciarse claramente en el hecho de que no tengan dificultades en clasificar los huevos de rana como seres vivos, y sin embargo, se observen conflictos en la clasificación de los huevos de gallina, quizá por ser este un "objeto" cotidiano utilizado para la alimentación humana de forma habitual. Otro hecho que no deja de sorprender, aunque sí entra dentro de lo esperado, es que pese a que la teoría celular se introduce en el último ciclo de la Primaria, y que se desarrolla a lo largo de la Secundaria, un porcentaje mínimo de estudiantes alude a la estructura celular como una de las características generalizables a todos los seres vivos. Un aprendizaje muy memorístico 
quizá también pueda explicar la dificultad creciente que hemos observado en la clasificación de la leche (el mayor porcentaje de error lo encontramos en los estudiantes de Grado), ya que al ser un producto de un ser vivo y al estar compuesto de materia orgánica, pone de nuevo en evidencia la confusión conceptual que no les permite discriminar lo vivo de lo no vivo. Por otro lado, aunque como ya hemos señalado, estos alumnos no mencionan explícitamente el movimiento como un atributo de lo vivo; sí es cierto que puede explicar los errores que cometen, asociando lo vivo con lo que se mueve (volcán), y lo inerte con aquello que se caracteriza por la ausencia de movimiento (judías, garbanzos, etc.).

En definitiva, como señalan De Manuel y Grau (1996), parece que los alumnos tienen ideas alternativas sobre los conceptos más generales e inclusivos relacionados con lo vivo (ser vivo, célula, animal y planta) y que éstas siguen estando presentes y con bastante relevancia en los ciclos superiores. Esto debe llevarnos a reflexionar sobre qué es lo que imposibilita la adquisición por parte de los alumnos de un concepto de vida acorde con la visión científica, pese a la presencia constante de los contenidos relativos a los seres vivos a lo largo de toda la educación formal.

\section{Implicaciones didácticas y formativas}

Teniendo en cuenta los resultados y conclusiones del estudio, se proponen los siguientes niveles de competencia en la clasificación de la materia, de menor a mayor complejidad:

- NIVEL 0: La materia se clasifica con criterios basados en la relación subjetiva de los objetos y seres vivos con el contexto y/o el sujeto. Los alumnos no son capaces de clasificar todo aquello que es más próximo a su entorno. Por ejemplo, se relaciona la bicicleta con la sangre por una relación causa-efecto: te caes de la bici $\mathrm{y}$ te haces sangre. Es un nivel próximo a la Educación Infantil.

- NIVEL 1: La materia se clasifica con criterios generales, tales como la funcionalidad, localización, la frecuencia de aparición y la procedencia. Los alumnos son capaces de clasificar todo aquello que es más próximo a su entorno. Por ejemplo, el criterio de funcionalidad relacionado con la comida.

- NIVEL 2: La materia se clasifica con criterios basados en las características observables de los objetos y seres vivos. Los alumnos son capaces de clasificar no solo aquello que es más próximo a su entorno. Por ejemplo, el criterio del estado físico en la materia inerte o la apariencia externa de los seres vivos.

- NIVEL 3: La materia se clasifica con criterios básicos basados en el concepto vivo (animal-planta)/no vivo (sustancia-mezcla). En este nivel, aún restringen la clasificación de la materia viva sólo a dos reinos, lo cual da origen a muchos errores. Aplican criterios fisiológicos y estructurales (requerimientos nutricionales, reproducción, presencia o no de órganos específicos, estructura celular, etc.) a los seres vivos y el criterio de la composición, asociado al concepto de sustancia y no 
a un material concreto. Los alumnos son capaces de clasificar objetos y seres vivos de los que tengan información a través de diversos medios, con las limitaciones de otras formas de vida y de las mezclas homogéneas no evidentes en las que no se aprecian sus componentes a simple vista.

- NIVEL 4: La materia se clasifica con criterios cientificamente aceptables, para categorizar contrastan la presencia de varios criterios y no se centran en uno solo. Los criterios manejados tienden a ser globalizadores y excluyentes, de forma que su presencia o no tenga relevancia. En este nivel para clasificar a un animal deberán verificar al menos varios de los siguientes criterios: tipo de nutrición (heterótrofa, se alimentan de otros seres vivos o de restos), movimiento autónomo, sistema nervioso y órganos sensoriales, organismo pluricelular. En el caso de las plantas: organismos pluricelulares, nutrición autótrofa (fotosíntesis, no se alimenta de otros seres vivos, obtienen la energía del sol), sin movimiento autónomo, sin sistema nervioso. Saben que la clasificación de la materia viva contempla cinco reinos, de los cuales conocen criterios científicos para describir el reino animal, el reino planta y el reino fungi. Para clasificar la materia inerte, además de la composición, han de tener en cuenta si la sustancia puede descomponerse en otras (compuesto) o no (elemento). Los alumnos son capaces de clasificar objetos y seres vivos de los que tengan información a través de diversos medios. Se trata de un nivel próximo a la Secundaria, es decir, el "techo conceptual" de la Primaria.

Los obstáculos más relevantes que dificultan el tránsito a un nivel de mayor complejidad son:

- Del Nivel 0 al Nivel 1, el principio de que solo se considera aquello con lo que se tiene una relación personal, de experiencias o incluso de afectos. Ejemplos de ello son: "Son cosas que no me gustan" $\left(2^{\circ}\right)$; "Es un virus que se te mete en el cuerpo y puedes morir" (4 $\left.4^{\circ}\right)$ " "Son malos" $\left(6^{\circ}\right)$

- Del Nivel 1 al Nivel 2, el principio de que solo se considera aquello ligado a un contexto. Ejemplos de ello son: "Son cosas del mar" $\left(2^{\circ}\right)$; "Son comestibles" $\left(4^{\circ}\right)$; "Son objetos cotidianos" $\left(6^{\circ}\right)$; "Se encuentran en el mar" (Grado)

- Del Nivel 2 al Nivel 3, el principio de que solo se considera aquello que se percibe (realismo ingenuo). Ejemplos de ello son: "No se mueven, no comen, no beben" $\left(2^{\circ}\right)$; "Son líquidos y gaseosos" (4 $4^{\circ}$; "La textura es la misma (dura)" (6 $)$; "Porque se mueven solos" (Grado)

- Del Nivel 3 al Nivel 4, el principio de considerar solo un criterio o varios no excluyentes y globalizadores. Ejemplos de ello son: "No respiran" (4\%); "Necesitan agua para vivir" (6 $\left.6^{\circ}\right)$; "Son seres vivos que se reproducen" (Grado)

Estamos de acuerdo con Martínez Losada, García y Rivadulla (2009) al proponer que, desde el ámbito escolar, se promoviese una visión unitaria de los distintos tipos de materia, abordando su estudio de forma que favorezca su caracterización y 
diferenciación, tanto desde un modelo macroscópico (en Primaria) como microscópico (en Secundaria). Las actividades escolares que pueden facilitar el tránsito a un nivel de mayor complejidad deberían ir orientadas a:

- Del Nivel 0 al Nivel 1: la manipulación de objetos y seres vivos en diferentes contextos que enriquezcan sus experiencias.

- Del Nivel 1 al Nivel 2: la observación de las características de los objetos y seres vivos.

- Del Nivel 2 al Nivel 3: la medida de las propiedades características de las sustancias y técnicas de separación de los componentes de una mezcla; y actividades prácticas que permitan conocer la relación entre las estructuras observadas en la materia viva y su función, más allá de la morfología externa.

- Del Nivel 3 al Nivel 4: la planificación y elaboración de protocolos para la clasificación de la materia que sean científicamente aceptables.

En la Figura 3 se indica el reparto de las muestras en los niveles de competencia propuestos. La muestra de Primaria se concentra mayoritariamente en el Nivel $1(40 \%$ de $2^{\circ}, 61 \%$ de $4^{\circ}$ y $35 \%$ de $6^{\circ}$ ) y en el Nivel $2\left(39 \%\right.$ de $4^{\circ}$ y $53 \%$ de $\left.6^{\circ}\right)$, el Nivel 0 está ocupado mayoritariamente por los alumnos de $2^{\circ}$ de Primaria (60\%), mientras que solo un alumno de $6^{\circ}$ ocupa el Nivel 3. Ningún alumno de Primaria está en el Nivel 4. La muestra de los estudiantes de Grado se reparte entre el Nivel $2(43.5 \%)$ y el Nivel 3 (51\%). Sólo un estudiante está en el Nivel 4 y dos en el Nivel 1.

Por otra parte, en el ámbito de la formación inicial de maestros es esencial el conocimiento de las concepciones de los alumnos de Primaria sobre los contenidos curriculares de ciencias, como el de la clasificación de la materia. Por una parte, porque como hemos visto, los futuros maestros, como producto de toda su experiencia personal, social y especialmente escolar, también manifiestan sus propias concepciones antes de iniciar el proceso de formación inicial, muy similar al de los alumnos de Secundaria, y hasta de Primaria. Y por otra parte, para los estudiantes de Magisterio no parece que sea una necesidad tener en cuenta las concepciones de los alumnos para llevar a cabo una enseñanza que facilite el aprendizaje. Por todo ello, el tratamiento de las concepciones de los alumnos tiene una gran potencialidad para hacer conscientes a los futuros maestros de su existencia e importancia para la enseñanza y el aprendizaje de las ciencias, y también, para facilitar la reestructuración de sus propias ideas en relación a los contenidos científicos en el ámbito escolar (Martín del Pozo, 2007). 


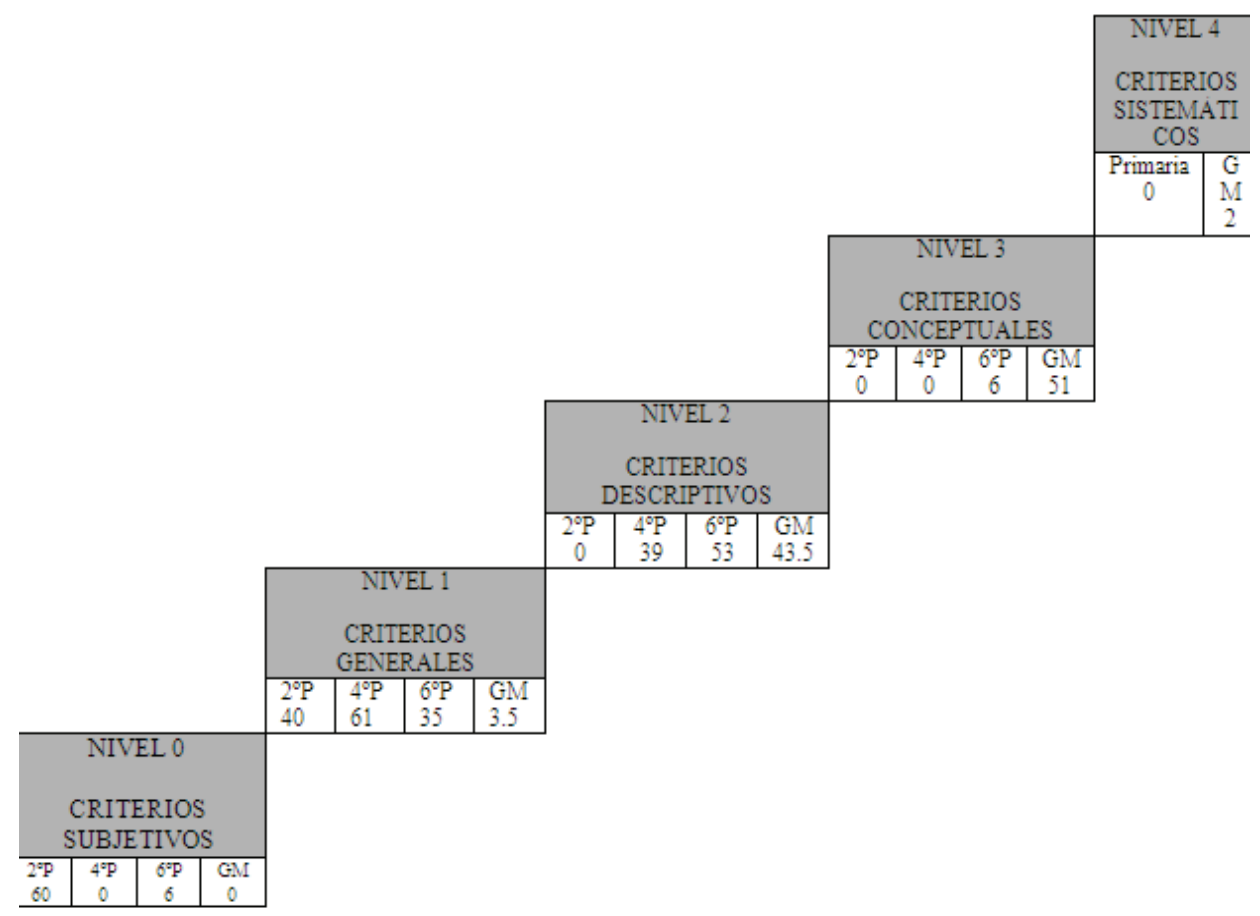

Figura 3. Porcentaje de alumnos de Primaria y de estudiantes de Grado de Maestro en cada nivel de competencia en la clasificación de la materia.

Finalmente, queremos apuntar algo que nos ha llamado poderosamente la atención. Como se ha podido constatar, también hemos trabajado con estudios realizados en las décadas de los setenta y ochenta, considerados clásicos en esta línea de investigación. Sorprende la escasísima influencia han tenido en la enseñanza y aprendizaje de las ciencias y en formación inicial de los maestros. A pesar de que se trata de un estudio con muestras reducidas, todas nuestras conclusiones no hacen sino confirmar en líneas generales lo que aquellos estudios concluyeron, y la pregunta sería: ¿qué tenemos que cambiar en nuestros sistemas educativos para que los resultados de la investigación preocupada por la mejora de la escuela contribuyan a transformar lo que ocurre en las aulas cuando se enseñan ciencias? 


\section{Referencias bibliográficas}

ASTOLFI, J.P. (1999). El "error" un medio para enseñar. Sevilla: Díada.

ASTOLFI, J.P. (2002). Conceptos clave en didáctica de las disciplinas. Sevilla: Díada.

BARDIN, L. (1986). Análisis de contenido. Madrid: Akal.

BRUMBY, M. (1982). Students perceptions of the concept of life. Science Education, 66(4), 613-622.

CABALLER, M.J. Y GIMÉNEZ, I. (1992). Las ideas de los alumnos y alumnas acerca de la estructura celular de los seres vivos. Enseñanza de las Ciencias, 10(2) 172180.

CAREY, S (1985). Conceptual change in chilhood. Cambridge. MA: MIT Press

CARRASCOSA, J. (2005). El problema de las concepciones alternativas en la actualidad (parte I). Análisis sobre las causas que la originan y/o mantienen. Revista Eureka sobre enseñanza y divulgación de las ciencias, 2 (2), 183-208.

CUBERO, R. (2005). Perspectivas constructivistas. La intersección entre el significado, la interacción y el discurso. Barcelona: Graó.

DRIVER, R., GUESNE, E. Y TIBERGHIEN, A. (1989). Ideas cientificas en la infancia y la adolescencia. Madrid: Morata-MEC.

DRIVER, R., SQUIRES, A., RUSHWORTH, P. Y WOOD-ROBINSON, V. (1999). Dando sentido a la ciencia en Secundaria. Investigaciones sobre las ideas de los niños. Madrid: Visor-Aprendizaje.

FURIÓ, C., SOLBES, J. Y CARRASCOSA, J. (2006). Las ideas alternativas sobre conceptos científicos: tres décadas de investigación. Alambique, 48, 64-77.

GARCÍA, M.B., MATEOS, M. Y VILANOVA, S.L. (2011). Contenido y naturaleza de las concepciones de profesores universitarios de biología sobre el conocimiento científico. Revista Electrónica de Enseñanza de las Ciencias, 10 (1), 23-39. En: http://www.saum.uvigo.es/reec/volumenes/volumen10/ART2_Vol10_N1.pdf

LOOFT, W.R. (1974). Animistic thought in children: understanding "living" across its associated attributes. Journal of Genetic Psychology, 124, 235-40.

LUCAS, A.M., LINKE, R.D, Y SEDGWICK, P.P. (1979). Schoolchildren's criteria for "alive" a content analysis approach. Journal of Psychology, 103,103-12.

MANUEL, J. de (1994). Idees alternatives sobre alguns conceptes de Biologia: "La formiga té els pulmons petits", "Un arbre no és una planta", L'elefant té les cèlules més grans que el ratolí”. Temps d'Educació, 11, 235-255.

MANUEL, DE J. Y GRAU, R. (1996): Concepciones y dificultades comunes en la construcción del pensamiento biológico. Alambique, 7, 53-63.

MARTÍN DEL POZO, R. (2007). Aprender a enseñar ciencias en Primaria. Sevilla: Díada. 
MARTÍNEZ LOSADA, C., GARCÍA BARROS, S. Y RIVADULLA LÓPEZ, J.L. (2009). Qué saben los/as alumnos/as de Primaria y Secundaria sobre los sistemas materiales. Cómo lo tratan los textos escolares. Revista Electrónica de Enseñanza de las Ciencias, 8 (1), 137-155.

MONDELO ALONSO, M., GARCÍA BARROS, S. Y MARTÍNEZ LOSADA, C. (1994). Materia inerte / materia viva ¿tienen ambas constitución atómica? Enseñanza de las Ciencias, 12(2), 226-233.

MONDELO ALONSO, M., MARTÍNEZ LOSADA, C. y GARCÍA GARROS, S (1998). Criterios que utilizan los alumnos universitarios de primer ciclo para definir ser vivo. Enseñanza de las ciencias, 16(3), 399-408.

OLIVA, J.M. (1999a). Algunas reflexiones sobre las concepciones alternativas y el cambio conceptual. Enseñanza de las Ciencias, 17 (1), 93-177.

OLIVA, J.M. (1999b). Ideas para la discusión sobre el cambio conceptual. Enseñanza de las Ciencias, 17(1), 115-117.

ORDEN ECI/2211/2007, de 12 de julio, por la que se establece el currículo y se regula la ordenación de la Educación Primaria (BOE 20 Julio 2007) En: http://www.boe.es/boe/dias/2007/07/20/pdfs/A31487-31566.pdf

ORDEN ECI/3857/2007, de 27 de diciembre, por la que se establecen los requisitos para la verificación de los títulos universitarios oficiales que habiliten para el ejercicio de la profesión de Maestro en Educación Primaria (BOE 29 Diciembre 2007). En: http://www.boe.es/boe/dias/2007/12/29/pdfs/A53747-53750.pdf

PIAGET, J. (1926). La representation du monde chez l'enfant. Paris: Alcan. (Trad. cast. La representación del mundo en el niño. Madrid: Morata, 1973.)

POSADA, J.M. (2000). El estudio didáctico de las ideas previas. En: F.J. PERALES y P. CAÑAL (dir.). Didáctica de las Ciencias Experimentales. Alcoy: Marfil.

POZO, J.I., SANZ, A., GÓMEZ, M.A. Y LIMÓN, M. (1991). Las ideas de los alumnos sobre la ciencia: una interpretación desde la Psicología cognitiva. Enseñanza de las Ciencias, 9(1), 83-94.

PRIETO, T., BLANCO, A. Y GONZÁLEZ, F. (2000). La materia y los materiales. Madrid: Síntesis.

STROMMEN, E (1995). How are living things alike and different? First graders' knowledge of basic life science concepts. Journal of Biological Education, 29 (4), 286-292.

TAMIR, P., GAL-CHOPPIN, R. Y NUSSNOVITZ, R. (1981). How do intermediate and junior high school students conceptualize living and non-living? Journal of Research in Science Teaching, 18(3), 241-248.

VOSNIADOU, S. (1994): Capturing and modelling the process of conceptual change. Learning and Instruction, 4 (1), 45-69. 


\section{Correspondencia con las autoras:}

Paloma Galán Martín y Rosa Martín del Pozo

Facultad de Educación

Departamento de Didáctica de las Ciencias Experimentales

C/ Rector Royo Villanova s/n

28040 Madrid

Tlf: 91-3946249

E-mails: pvascogalan@gmail.com y rmartin@edu.ucm.es 